\title{
Using the Personal Construction of Technology Use (PCTU) Theory to understand students' information, technology and inquiry learning experiences in the blended classroom
}

\author{
Dr Lyn Hay \\ Senior Lecturer, Division of Teaching \& Learning, Charles Sturt University \\ Director, Leading Learning Institute \\ lhay@csu.edu.au
}

\section{Introduction}

This paper presents a new theory called the 'Personal Construction of Technology Use' (PCTU) Theory [Hay 2017]. This theory provides an explanation of how students' experiences with learning technologies influence their views on using these technologies to support their learning. The development of this theory is based on doctoral research that explored the ways specific Web 2.0 technologies were utilised by students while undertaking inquiry projects. This paper outlines the domains, dimensions, processes and principles of the PCTU Theory, and demonstrates how educators can employ PCTU Theory to better understand the complex nature of students' information, technology and inquiry learning experiences within a blended classroom environment.

\section{Statement of the Problem}

The focus of this doctoral study [Hay, 2017] was to examine how Web 2.0 technologies could be used to support secondary school students as inquiry learners, and the different types of instructional intervention that a teacher librarian (TL) and class teacher can provide in the context of this kind of learning task. It also explored how student learning styles might impact on students' levels of use of Web 2.0 technologies when undertaking inquiry on a topic of personal interest, and how student, teacher, and TL experiences with

Web 2.0 technologies might influence their views on using these in the future to support learning. A review of the literature providing a context for this problem statement will be provided in the full paper.

\section{Methodology}

The study adopted ethnography as the overarching methodological approach and used a mixed methods approach to the collection of qualitative and quantitative data. Constructivist learning theory was used as an interpretivist lens for exploring the participants' inquiry and technology experiences in the study, with Personal Construct Theory (Kelly, 1963), Social Construction Theory (Berger \& Luckmann, 1967), and Vygotsky's (1978) Zone of Proximal Development used in interpreting the qualitative data, and informing the development of the PCTU Theory. Entwistle and Tait's (1997) Approaches and Study Skills Inventory for Students (ASSIST) was used to explore 
students' approaches to learning and technology use. Details of research design, research site and participants, data collection and analysis will be presented in the full paper.

\section{Findings}

The study identified seven broad functions that Web 2.0 technologies can provide students, teachers and TLs while undertaking inquiry projects, and the author developed a Technology Functionality Matrix as a scaffold to identify the features and functionality of the Web 2.0 tools to assist those interested in trialing one or more of these tools. The study also identified a set of seven criteria for determining technology use (CDTU) which students apply when critically evaluating technologies that are available to them to support their learning. In addition, the study identified three mental models of technologies - vagueness, technicality and enrichment - which could influence the way individual's approach the use of technologies.

The concept of a student's personal technology toolkit (PTT) was identified as a key element impacting on a student's approach to technology use, with this toolkit representing those technologies students had adopted as their preferred or default suite of tools and techniques to meet their learning and personal needs. It was found when students are given a choice to use technologies to support their learning, they will draw upon their own personal suite of tools and techniques to complete learning tasks, unless they are exposed to other tools or techniques that could help them complete a task more efficiently, effectively or creatively than they would achieve with their existing toolkit.

The concept of a students' individual learning team was also identified. The study showed how students (by Year 10) have the capacity to independently construct and maintain their own learning team that draws upon a mix of teachers, TLs, classmates, family, friends, and outside experts, based on five types of expertise the student perceives these individuals bring to the inquiry experience. Furthermore, the study identified the potential of Web 2.0 technologies as a platform for teachers and TLs to provide eight different types of instructional intervention when supporting students undertaking inquiry.

\section{Discussion and Implications}

As a result of the above findings, the author drew upon the fields of information behaviour and use, teaching and learning, technology use and adoption, and constructivist learning theory to develop a new interdisciplinary theory to assist teachers' understanding of how students' experiences with specific online technologies can influence their views on using these technologies to support learning. The Personal Construction of Technology Use (PCTU) theory is comprised of two domains: (a) the blended classroom and an inquiry unit as a socially constructed domain; and (b) the student experience as a personally constructed domain, as illustrated in Figure 1.

Figure 1 The social and personal constructs of a blended classroom 


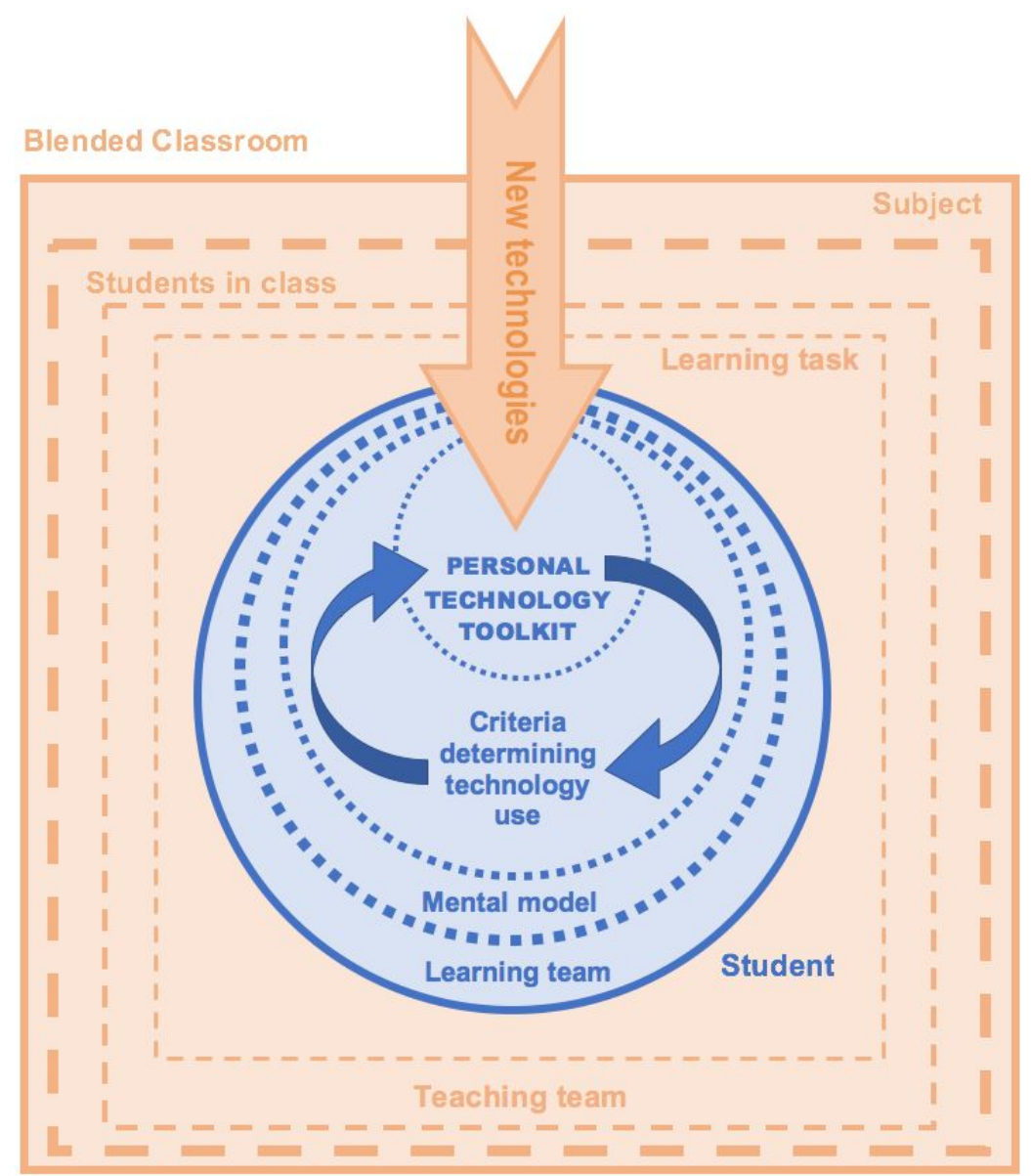

Each domain consists of a set of dimensions and processes that contribute to the construction of that domain. For example, the blended classroom as a socially constructed domain consists of five dimensions, including a class of students, the specific subject they are enrolled in, the teaching team, the inquiry unit, and the new technologies being introduced to the class. While the personally constructed domain of a student consists of four dimensions, including a student's learning team, their mental model of technology, the set of criteria (CDTU) they apply to make decisions whether to use technologies to support their learning, and the nature of their PTT.

This theory posits technology evaluation as a process of personal construction, and presents a set of seven Technology Evaluation principles to help explain the personal construction process experienced by a student when faced with the choice of using one or more technologies to support their learning. These principles have been shaped by seven of Kelly's (1970) personal construct corollaries to provide a framework for examining students'

decision making process when evaluating the technologies available. These seven principles of construction, individuality, organisation, dichotomy, choice, range and experience will be described in detail in the full paper.

The theory explores the above domains, dimensions and processes from the perspective of the student, i.e., the theory is presented as a student-centric model of inquiry within the blended classroom environment, with the development of a student's PTT as an outcome of the PCTU experience. The author will present a number of implications of the PCTU theory within the context of professional practice for teachers and TLs, and also present the implications of this theory for researchers and identify the ways components of PCTU could be examined in future studies. 


\section{References}

Berger, P. L., \& Luckmann, T. (1967). The social construction of reality: A treatise in the sociology of knowledge. London: Allen Lane.

Entwistle, N. J., \& Tait, H. (1997). Scoring key for the approaches and study skills inventory for students. In Approaches and Study Skills Inventory for Students (ASSIST). Edinburgh: Centre for Research on Learning and Instruction, University of Edinburgh. Retrieved from http://www.tla.ed.ac.uk/etl/questionnaires/ASSIST.pdf

Hay, L. (2017). "Do we have to use a wiki, Miss?" How Web 2.0 technologies can support students as inquiry learners in a secondary school. Doctoral dissertation, Charles Sturt University, Australia. Retrieved from https://researchoutput.csu.edu.au/en/publications/do-we-have-to-use-a-wiki-miss-how-web-20 -technologies-can-support

Kelly, G. A. (1963). A theory of personality: The psychology of personal constructs. New York: Norton.

Vygotsky, L. S. (1978). Mind in society: The development of higher psychological processes. Cambridge, MA: Harvard University Press.

\section{Biography}

Dr Lyn Hay is a Senior Lecturer and Online Learning Innovation Leader with the Division of Learning \& Teaching at Charles Sturt University. Previous to this appointment, Lyn worked as Lecturer in Teacher Librarianship at the School of Information Studies, Charles Sturt University from the mid-1990s. Her scholarly work focuses on school library futures, principal-TL partnerships, school library impact and evidence-based practice, and students' use of technologies to support learning. Lyn is also Director of the Leading Learning Institute, a think tank providing educational consultancy services for schools, specialising in vision building to inform the design and refurbishment of school libraries, and assisting teacher librarians in collecting and analysing data to demonstrate evidence of impact. Lyn also currently holds the position of Vice President for the School Library Association of New South Wales (SLANSW) in Australia. 